\title{
Tourism in the Russian Federation: the impact of Covid-19 on the current state and prospects of development in the coronavirus pandemic
}

\author{
Nadezhda Agaeva*, Irina Shchetilina, Elena Kovaleva \\ Voronezh State University of Engineering Technologies, Voronezh, Voronezh Region, Russia
}

\begin{abstract}
Tourism is one of the most profitable sectors of the economy, bringing up to $25 \%$ of GDP in developed countries. Unfortunately, external conditions are sometimes irresistible and have a direct positive and negative impact. This is exactly what happened in 2020. The year 2020 was a huge test for the entire globe and forced humanity to pay a huge price. In different parts of the world, the impact of Covid-19 and the subsequent protracted pandemic has been experienced in different ways. The peculiarities of the spread and further penetration of the virus are connected with the countrys' economy, with the amount of resources that state governments had the opportunity to send to support the most affected industries and residents. Considering various industries, it is impossible not to mention the tourism sector, which has suffered enormous losses and required new directions in its development, the opening of fundamentally new sales channels and directions of movement, characterized by a significantly expanded geography across the country. Based on this, it is important to determine what is the current state and future prospects and trends in the development of the industry. What is the pace of recovery, and what lessons have we learned from the historic 2020 pandemic.
\end{abstract}

\section{Introduction}

Figuratively speaking, we can say that the tourism sector has become one of the main victims of Covid-19. Based on international studies, most European countries have quite large revenues from the tourism sector, but at the same time, tourist spending also has a high growth trend, which levels the gap in the corresponding indicators between countries [1].

\subsection{Related Work}

We in this study, empirical methods (description, comparison, modelling), general logical methods (analysis, synthesis, generalization, analogy), methods of economic analysis (expert assessments) are used as methods of scientific research.

\footnotetext{
${ }^{*}$ Corresponding author: nadinn ktn@mail.ru
} 
Based on the situation related to the 2020 pandemic, without global preliminaries, we can conclude that the tourism sector was among the most affected by Covid-19. The imposed bans and restrictions, which practically nullified all types of tourism both at the external and internal levels, led to the minimization of the profits of tourism campaigns, at the same time, no one removed their obligations to pay wages to employees and compliance with sanitary and epidemiological safety measures [2]. Of course, the coronavirus pandemic has caused irreparable damage to the tourism sector, but at the same time, some positive aspects cannot be excluded, and they will determine the further development of campaigns and their format, further work in the tourism sector. For some campaigns, total travel restrictions will become a positive experience in introducing various online formats of interaction with consumers, searching for new solutions in the formation of tours, working in small groups, and total re-profiling is not excluded, in order to find new alternative solutions in the domestic tourism market. It is impossible not to note the complete change in the direction of the vector of work of tourism organizations, which was reoriented during the pandemic from external tourism to internal. The change of landmarks has expanded the geography of tourist destinations as much as possible. Tours to Altai, Baikal, Volga, Siberia and the Far East were added to the classic southern destinations, which provided serious competition to traditional trips of Russian tourists.

The analysis of studies conducted by many world agencies, including KPMG, helped to draw several main conclusions on the situation with the pandemic and its impact on the tourism sector. The first and most important thing is that the tourism sector has suffered the most from the Covid-19 pandemic. During this period, it is impossible not to note the organized support measures from the state: grace periods for loan payments, subsidies to small and medium-sized businesses, mortgage holidays, and interest-free loans for paying salaries to employees, a cashback program when traveling around Russia. The most common measures used by respondents were wage subsidies. Naturally, these measures made it possible to level the unemployment rate in the tourism sector, as well as to support campaigns that do not have large financial reserves. From which follows the second conclusion, which indicates that as a result of a survey of heads of tourism organizations, it was revealed that $87 \%$ of respondents took advantage of state support measures.

Focusing on the current situation of the spread of coronavirus infection, the fourth conclusion suggests itself, which dictates full and unconditional compliance with safety rules, both during the pandemic and the post-pandemic period. Naturally, this is dictated by the current epidemiological situation, and is a response to consumer requests. At this stage, all organizations that resume work again, being in daily competition, are fully focused on compliance with sanitary and epidemiological safety standards [2].

According to the KPMG agency, the demand for travel services fell to zero for about $56 \%$ of respondents surveyed. It is possible to identify the most affected areas of tourism and population groups. The categories of the population in which demand has fallen largely (a decrease of 60.5\%) are the able-bodied population aged 35-60 years, which is due to the state of incomprehensibility and uncertainty, especially from the point of view of the safety of trips with children. Pensioners (46\% decrease) follow them and the able-bodied population aged $18-35$ years $(41.5 \%)$. Analyzing the respondents' answers on optimizing the number of staff, it can be concluded that about $53 \%$ of organizations were able to stay on the market by receiving state subsidies and maintain full-time staff with full salary.

About $37 \%$ (in total by category) will have to reduce the salary component from 25 $50 \%$ of employees. Considering the "species" diversity of tourism, the most affected are cultural, educational, event and business types of tourism, however, respondents also noted a decrease in demand for health-improving and beach tourism.

1. Cultural, educational and event tourism, in which the objects of display, public spaces that were hit by the pandemic in the first place, due to long-term restrictions on visits, 
suffered the most, demand for this type fell by 58\%. Moreover, it should be noted that in a number of territories such organizations have not resumed their work now.

2. Health-improving and beach tourism demand fell by $48 \%$. However, the situation was mitigated by the fact that many tourists, cancelling foreign trips, went on tours in Russia, which again was dictated by the uncertainty of the situation with the pandemic abroad, as well as the growth of the exchange rate [3-5].

3. Business tourism, the demand for which has decreased by $42 \%$. Moreover, it should be noted that the pandemic has had a significant impact on this segment. There has been a reduction in a large number of business trips and the transfer of events to an online format, which will not lose its relevance in the future.

\subsection{Our Contribution}

This paper presents some facts, that the pandemic has caused enormous damage to the economies of all countries of the world. The leaders of all countries took unprecedented measures to support various sectors of the economy and, as a result, measures to restore the most severely affected industries. The tourism industry is no exception. To combat coronavirus infection, government support measures were taken, which allowed many enterprises to stay "afloat". It is possible to highlight the main measures taken to restore the tourism sector: full exemption or postponement of tax payments; deferral of loan payments; managing unemployment by increasing benefits and developing digital skills; creation of partnership funds aimed at the restoration of the tourism sector; dynamic development of information processing systems in order to adjust marketing strategies; comprehensive work on the correct organization of domestic tourism, the development of new tourism products, as well as the provision of discounts to certain categories of citizens within the framework of advertising programs.

All this requires a lot of attention and dictates to organizations the need to review the work of travel companies, the choice of new destinations and consumer segments.

Speaking about the reorientation of the tourism industry, the fifth conclusion can be stated that, according to $50 \%$ of respondents, the re-profiling will not affect all representatives of tourist facilities and accommodation, as well as excursion organizations. This fact will affect mainly travel agents and tour operators. This is very logical, because changing the profile will affect the organizations that have been most affected by the pandemic, and previous areas of work may be associated with losses when the period of total restrictions returns. The most appropriate changes in the profile change are the transition from working with large groups to providing personalized services to small groups with an emphasis on consumer demand.1.3. Paper Structure

The rest of the paper is organized as follows. Based on the reorientation, we can talk about the key trends in the tourism sector in section 2. Focusing on them, it is possible to determine how the tourism sector is developing at the present stage and what benchmarks can be laid for 2022. Finally, Section 3 concludes the paper and presents direction for future research.

\section{Background}

\subsection{Research Results}

At this stage, there are many forecasts about what awaits the tourism sector in the near future and what the prospects for recovery are in 2022. Based on the opinion of Natalia Zaitseva, Professor of Plekhanov Russian University of Economics, we can conclude the 
following. The low number of residents who have a desire to leave the Russian Federation is naturally associated with the coronavirus pandemic (it is about 1\% of IA REGNUM). Moreover, the low percentage of those wishing to travel abroad is due more to the consequences of the pandemic than to the problem of infection itself. It should be noted that the income part of the population has decreased due to the intensive growth of exchange rates (dollar and euro). Also, it is impossible not to pay attention to a certain "information vacuum". Data on the number of cases abroad may be in doubt, the effectiveness of vaccination has not been fully confirmed, respectively, the risk of infection is very high. These facts contribute to the fact that even if it is possible to travel outside the Russian Federation on vacation, residents prefer to take advantage of the opportunities of domestic tourism, or rest outside the city.

According to Natalia Zaitseva, it is premature and very problematic at this stage to make any forecasts regarding the expectations of the tourism sector for 2022. This is facilitated by the fact that the situation is changing very dynamically. The virus mutates, which contributes to the emergence of new Covid-19 strains. The developed measures to prevent the spread of Covid-19 do not keep up with the changes of the virus itself. All types of tourism directly depend on the development of the coronavirus pandemic, and the response of states to these changes. The third conclusion follows from this, even if we assume the most optimally optimistic scenario, the tourism sector could recover even in 2022. However, there is a version that it takes at least 3 years to reach the level of 2019. The dynamics of the recovery of the industry can have two ways. The first one is more intensive, directly depends on the lifting of travel restrictions, which gives rise to the effect of deferred demand [6-8]. The second, more realistic and optimistic, suggests that companies suffered huge losses during the pandemic, as well as the solvency of citizens decreased, which contributes to slowing down the process of restoring the sphere to the pre-pandemic level. In this regard, the most popular types of tourism are beach and healthimproving.

\subsection{Discussion of the Results}

Therefore, there are two scenarios for the recovery of the tourism sector: moderately optimistic and conservative.

In the first case, the expected recovery period is 2022. Figure 1 shows Evromonitor International's baseline forecast for the restoration of inbound and outbound tourist flows in Russia.

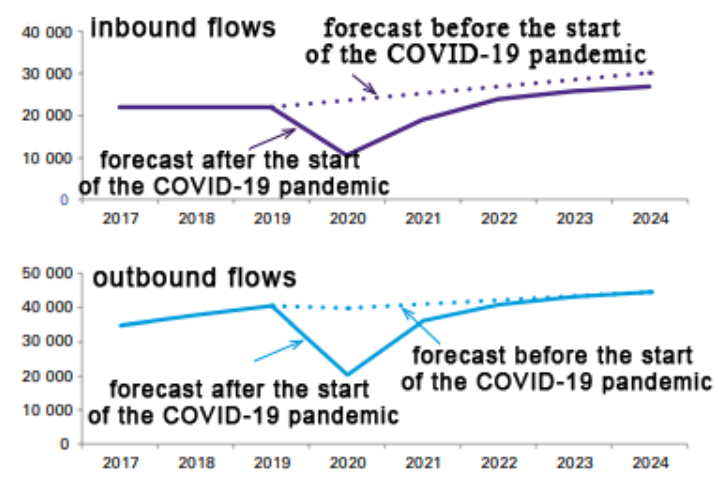

Fig. 1. Evromonitor International's baseline forecast for the restoration of inbound and outbound tourist flows in Russia, thousand trips. 
Based on this forecast, we can draw the following conclusion that if the spread of the coronavirus decreases and it becomes possible to control it, it can be assumed that external and internal tourist flows will recover in 2022, which fully coincides with the opinion of the majority of respondents to the KPMG study.

In the second case, the expected recovery period is 2023 and later. Figure 2 shows the pessimistic forecast of Evromonitor International for the restoration of inbound and outbound tourist flows in Russia.

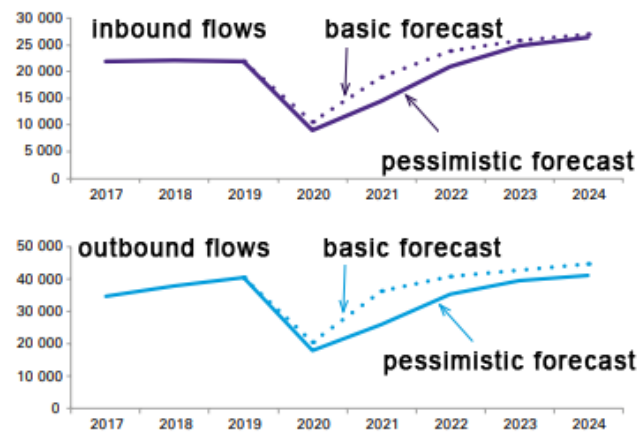

Fig. 2. The pessimistic forecast of Evromonitor International for the restoration of inbound and outbound tourist flows in Russia, thousand trips.

According to this forecast, due to the fact that the coronavirus pandemic will cover most of the world space, tourist flows will recover by 2023 and 2024.

It is impossible not to pay attention to the fact that some of the respondents say that preand post-pandemic indicators will differ due to strong changes in the industry: changing the orientation of service providers to meet the needs of consumers; partial re-profiling of travel services companies, including the transition to an online format; reduction of the number of companies [9].

Both in the first and in the second case, the development of scenarios will completely depend on the lifting of restrictions on the Covid-19 pandemic, as well as the general economic situation in the country and in the world.

Tourism organizations that resume their work after partial or complete suspension of activity, as the main tool for attracting consumers, allocate full implementation of measures of sanitary and epidemiological regulations, which forms the maximum possible consumer safety.

Focusing on the results of KPMG research, industry representatives plan to use several main ways to attract customers: advertising; availability of shares; price reduction. In addition, the tourism market players are ready to apply the following measures in their work: search for new niche solutions; development and implementation of new products; development of personalized solutions.

\section{Conclusion}

The prospects for the restoration of various types of tourism have different terms and depend on restrictions. Speaking about the beach type of tourism, we can state the fact of a faster recovery. These types of tourism have the greatest demand and popularity, and have a high accessibility factor among most groups of the population. 
The health-improving type of tourism also claims to have a high rate of recovery due to objective reasons. It is aimed at restoring the strength and health of citizens who were not affected by the pandemic; the first facilities that started working after the removal of restrictions from the pandemic were the institutions with a medical license. The growing demand for medical tourism is a global trend. In the Russian Federation, it is associated with the development of preferential programs and the implementation of national projects. Therefore, a number of medical organizations have introduced Covid-19 rehabilitation programs as an additional profile.

Speaking of all other types of tourism, their popularity will depend on the personalized range of services provided in favor of small groups with individual needs. We think that business tourism will not be as popular now as it used to be. First, this is because it is convenient to solve many issues that arise when doing business during video conferences.

Based on the above information, it is possible to determine the main trends in the development of the industry. The first and most important is the transition to the rails of domestic tourism as an alternative to external tourism. In the context of Russia, we can say with full confidence that the transition to internal movement has many advantages. This includes the preservation of cultural heritage, historical and cultural values, and the study of specially protected areas. Russia is the country that is in second place in terms of the rate of recovery of domestic tourism. For the second year in a row, there has been a dynamic increase in domestic trips focused on the following destinations: Karelia, the Urals, Ingushetia, Chukotka, Magadan, Buryatia, and Altai.

The second important trend is a decrease in the depth of purchases. In the pre-pandemic period, purchases of tours were made a month before departure, and tickets for departure 10 days in advance. Now the purchase of tickets takes place the day before due to the fear of consumers canceling the flight and non-refund of money for hotel reservations. Certain parts of the companies have already reacted to this trend by reducing the period to a few days. Naturally, this measure does not eliminate the risks, but at the same time, there is a better chance that the country will not be closed three days before departure.

The decrease in the number of direct flights, the unstable situation in the world, dynamically changing rules of arrival and departure of aircraft, restrictions in countries, all this leaves its mark on the departure of tourists. Knowledgeable tourists pick up flights themselves, those who are planning a foreign trip for the first time, postpone the trip until better times. In particular, the risk of infection in the aircraft itself is not excluded.

The concept of business pleasure. In the presence of a large number of employees working remotely, they have the opportunity to rest at any time of the year. In this connection, a new set of requirements for hotels has appeared stable high-speed Internet, space for working with ergonomic furniture and accessible sockets. Figure 3 shows a number of changes in consumer preferences. 


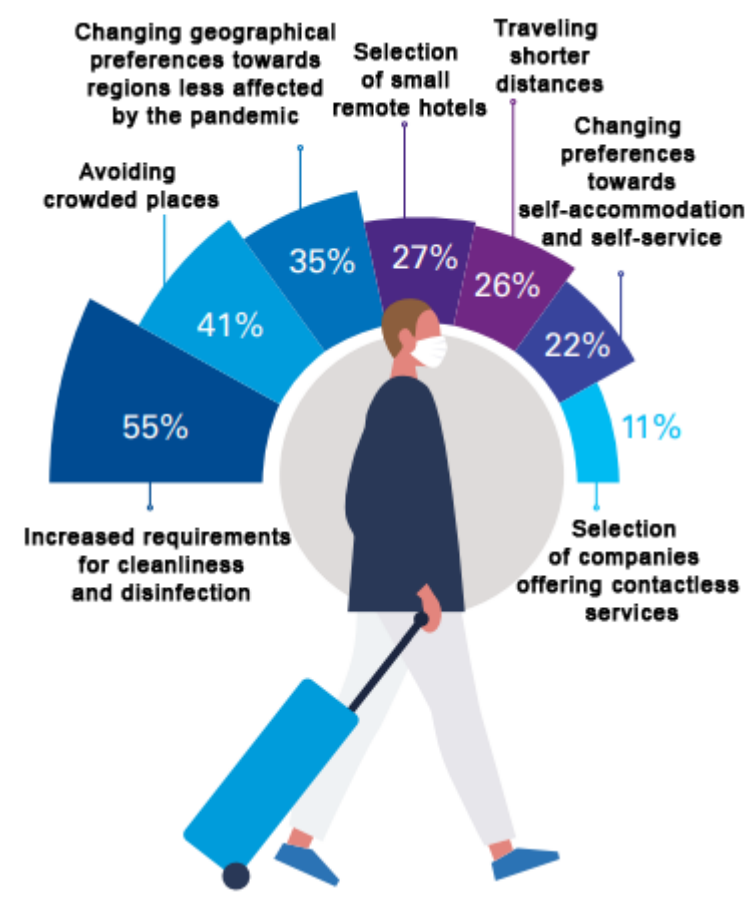

Fig. 3. Changes in customer preferences due to the pandemic.

But the key trend in the development of tourism in Russia is maximum digitalization. Get acquainted with the sights, plan a tour online, visit the exhibition, 24/7 support. Along with this, it is impossible not to note the increase in the volume of online sales and aggregators of package tours. An increase in online bookings was observed earlier, but during the pandemic they significantly strengthened their positions. In addition, an increase in online sales through their websites is expected. A significant increase in app sales is expected. This fact requires high-quality employees who are able to master the transition to digital tools, if the qualifications are insufficient, then such companies will lag far behind digital leaders $[10,11]$.

Considerable attention should be paid to changing the guidelines in the promotion channels. Traditional advertising does not justify itself, while digital advertising shows its effectiveness. In this connection, social networks can be an effective advertising platform.

The identification of new niches can become an active solution in the development of personalized tours, author's solutions aimed at an individual consumer or a specific group of consumers with their individual request. There is a decrease in demand for mass types of tourism, and routes with non-standard solutions in their program are becoming increasingly popular. Experts note that ecotourism and slow travel will become more in demand (a travel concept based not on a quick change of tourist places, but on full immersion in the culture of a new country, acquaintance with local residents, their traditions).

\section{Acknowledgment}

This work was supported by Voronezh State University of Engineering Technologies. 


\section{References}

1. Mezhdunarodnoe issledovanie UHY: dolja turizma v VVP raznyh stran (2018). Access mode: http://collegia.by/info/news/2018/mezhdunarodnoe-issledovanie-uhy-dolyaturizma-v-vvp-raznykh-stran/

2. N. Agaeva, I. Shchetilina, E. Kovaleva, Cruise tourism as a factor of sustainable development of the territories of the Russian Federation, E3S Web Conf., 295, 01041 (2021). Access mode: https://doi.org/10.1051/e3sconf/202129501041

3. M.O. Rabin, D.S. Scott, Finite automata and their decision problems, IBM J. Res. Dev., 3(2), 114-125 (1959). Access mode: https://doi.org/10.1147/rd.32.0114

4. N. Popova, I. Shchetilina, Y. Pisklyukova, N. Agaeva, Development of minced fish semi-finished products enriched with polyunsaturated fatty acids, E3S Web of Conferences, 279, 03024 (2021). Access mode: https://doi.org/10.1051/e3sconf/202127903024

5. H. Zabihi, M. Alizadeh, I. Wolf, M. Karami, A. Ahmad, H. Salamian, A GIS-based fuzzy-analytic hierarchy process (F-AHP) for ecotourism suitability decision making: A case study of Babol in Iran, Tourism Management Perspectives, 36, 1007262020 (2020). DOI: 10.1016/j.tmp.2020.100726

6. C. D'Souza, M. Taghian, T. Marjoribanks, Sustainability for ecotourism: work identity and role of community capacity building, Tourism recreation research, 44(4), 533-549 (2019)

7. T. Cheng, C. Wu, J. Wang, Community Participation as a mediating factor on resident's attitudes towards sustainable tourism development and their personal environmentally responsible behaviour, Current issues in tourism, 22(14), 1764-1782 (2019)

8. I. Shchetilina, N. Sandrakova, D. Chichkan, A. Shevchenko, V. Cherednyakova, Assessment of trends and prospects for the development of the public catering market of the Central Black Earth Economic Region of Russia, Economics and Entrepreneurship, 5 (118), 409-420 (2020)

9. S. Tikhomirov, I. Avtsinov, Ya. Turovsky, A. Surovtsev, A. Adamenko, E. Kovaleva, Hardware and software complex for managing biotechnological systems using intelligent information technologies, Bulletin of Voronezh State University, Series: System Analysis and Information Technologies, 3, 158-165 (2019)

10. N. Agaeva, T. Alekseeva, E. Krivenko, I. Nesterenko, E. Taltynova, A. Stolyarov, Theoretical aspects of the use of alfalfa in the production of flour confectionery products of high biological value for tourist routes, P2ARM 2020 IOP Conf. Series: Earth and Environmental Science, 640, 022041 (2021). DOI:10.1088/1755$1315 / 640 / 2 / 022041$

11. A. Martinis, K. Kabassi, G. Karris, Unveiling the Profile of Tourists in Islands with Protected Areas to Promote Sustainable Tourism, 5th International Conference of the International-Association-of-Cultural-and-Digital-Tourism (IACuDiT), Smart tourism as a driver for culture and sustainability (2019). DOI: 10.1007/978-3-030-03910-3_19

12. V. Katsoni, Marival Segarra-Oña, Smart Tourism as a Driver for Culture and Sustainability: Fifth International Conference, IACuDiT (2018) 